\title{
Virgin olive oil: a key food for cardiovascular risk protection
}

\author{
María-Isabel Covas ${ }^{1,2,3 *}+$, Rafael de la Torre ${ }^{2,4}$ and Montserrat Fitó ${ }^{1,2}$ \\ ${ }^{1}$ Cardiovascular Risk and Nutrition Research Group, Barcelona, Spain \\ ${ }^{2}$ CIBER de Fisiopatología de la Obesidad y la Nutrición, IMIM - Institut Hospital del Mar d' Investigacions Biomèdiques, \\ Barcelona, Spain \\ ${ }^{3}$ NUPROAS (Nutritional Project Assessment) Handesbolag (NUPROAS HB), Nackă, Sweden \\ ${ }^{4}$ Human Pharmacology and Neurosciences Research Group, Barcelona, Spain
}

(Submitted 17 June 2014 - Final revision received 28 November 2014 - Accepted 5 January 2015)

\section{Abstract}

Olive oil is considered to be one of the most healthy dietary fats. However, several types of olive oils are present in the market. A key question for the consumer is: What of the olive oils is the best when concerning nutritional purposes? With the data available at present, the answer is: the Virgin Olive Oil (VOO), rich in phenolic compounds. On November 2011, the European Food Safety Authority released a claim concerning the benefits of daily ingestion of olive oil rich in phenolic compounds, such as VOO. In this review, we summarised the key work that has provided the evidence of the benefits of VOO consumption on other types of edible oils, even olive oils. We focused on data from randomised, controlled human studies, which are capable of providing the evidence of Level I that is required for performing nutritional recommendations at population level.

\section{Key words: Virgin olive oil: polyphenols: hydroxytyrosol: tyrosol: cardiovascular risk}

Olive oil is the primary source of fat in the Mediterranean diet (MedDiet), which is associated with a low mortality for $\mathrm{CVD}^{(1)}$. In spite of this, data concerning olive oil consumption and primary end points for CVD, as well as for total mortality, have only been provided recently. Results of large EPIC (European Prospective Investigation into Cancer and Nutrition) cohorts have shown an inverse relationship between olive oil consumption and CHD mortality and incidence ${ }^{(2-4)}$. Also, results of the Three-City Study have shown an inverse relationship between olive oil consumption and stroke risk in women ${ }^{(5)}$. Recent results of the PREDIMED (Prevention by Mediterranean Diet) study have shown that consumption of extra-virgin olive oil (VOO), within the frame of the MedDiet, reduces the risk of atrial fibrillation in elder, high cardiovascular risk individuals $^{(6)}$. A large body of knowledge exists providing evidence of the benefits of olive oil consumption on secondary end points for CVD. Olive oil consumption has proven to promote benefits on lipid profile, insulin sensitivity, lipid and DNA oxidation, inflammation, endothelial function, thrombotic factors and blood pressure ${ }^{(7)}$ (Fig. 1). Due to this, on November 2004, the Federal Drug Administration of the USA permitted a claim on olive oil labels concerning: 'the benefits on the risk of CHD of eating about two tablespoons (23g) of olive oil daily, due to the monounsaturated fat (MUFA) in olive oil'. To achieve this possible benefit, olive oil is to replace a similar amount of saturated fat and not increase the total number of calories you eat in a day, ${ }^{,(8)}$.

Abbreviations: EUROLIVE, The effect of olive oil consumption on oxidative damage in European populations; MedDiet, Mediterranean diet; OHTyr, hydroxytyrosol; SBP, systolic blood pressure; Tyr, tyrosol; VOO, virgin olive oil.

*Corresponding author: Dr M.-I. Covas, email maria.nuproas@gmail.com

† Spanish Office: Apartado de Correos 93, Cassà de la Selva, 17244 Girona, Spain.

Publication of these papers was supported by unrestricted educational grants from Federación Española de Sociedades de Nutrición, Alimentación y Dietética (FESNAD), International Nut and Dried Fruit Council (INC), International Union of Nutritional Sciences (IUNS), Fundación Iberoamericana de Nutrición (FINUT), Centro de Investigación Biomédica en Red de la Fisiopatología de la Obesidad y Nutrición (CIBERobn) and Centro Interuniversitario di Ricerca sulle Culture Alimentari Mediterranee (Ciiscam). The papers included in this supplement were invited by the Guest Editors and have undergone the standard journal formal review process. They may be cited. The Guest Editors declare that Salas-Salvadó is a nonpaid member of the World Forum for Nutrition Research and Dissemination of the International Nut and Dried Fruit Council. Angel Gil is President of the Fundación Iberomericana de Nutrición, which is a non-paid honorary position. Lluis Serra-Majem is the President of the Scientific Committee of the Mediterranean Diet Foundation and Scientific Director of the CIISCAM (Centro Interuniversitario di Ricerca sulle Culture Alimentari Mediterranee), Universita La Sapienza di Roma which are both non-paid, honorary positions. Goretti Guasch is the Executive Director and Member of the Executive Committee of the International Nut and Dried Fruit Council, which is a paid position. Mònica Bulló declares no conflict of interest. 


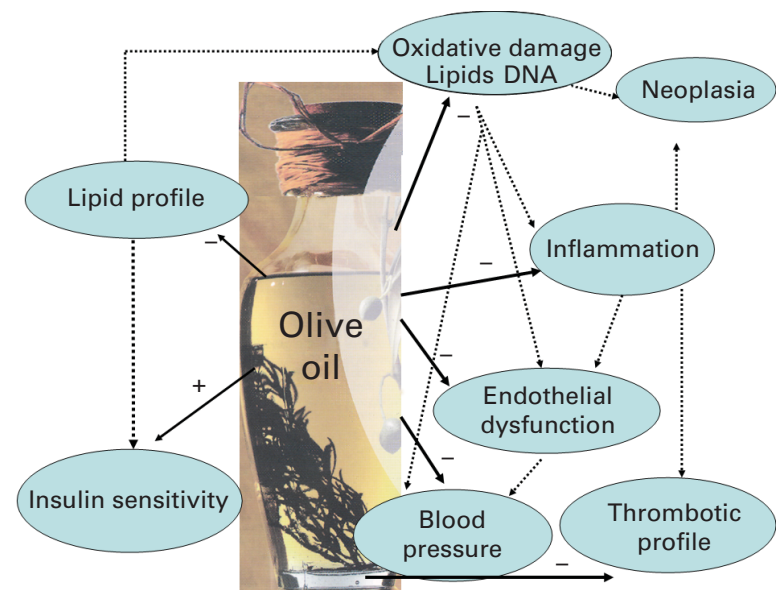

Fig. 1. Benefits of olive oil consumption on secondary end points for CVD. A colour version of this figure can be found online at http://www.journals. cambridge.org/bjn

The major components of olive oil are fatty acids, of which the MUFA oleic acid represents from 55 to $83 \%$ of the total fatty acids, PUFA from 4 to $20 \%$ and SFA from 8 to $14 \%$. The minor components of olive oil constitute from 1 to $2 \%$ of the total content of an olive oil. They are classified into two types: (1) the unsaponifiable fraction that could be extracted with solvents after the saponification of the oil and contains squalene and other triterpenes, sterols, tocopherols and pigments; (2) the soluble fraction that includes the phenolic compounds, which are the most studied and best-known components in terms of their benefits for health ${ }^{(9)}$. The content of the minor components of an olive oil varies depending on the cultivar, climate, ripeness of the olives at harvesting and the processing system used to produce the olive oil. Olive oils currently present in the market are extra-virgin, virgin, olive oil (EU regulation $2568 / 1991$ ) or pomace olive oil ${ }^{(10)}$. VOO are obtained from the fruit of the olive tree solely by mechanical or other physical means under conditions that do not lead to alteration in the oil. They have not undergone any treatment other than washing, decantation, centrifugation or filtration. Oils obtained using solvents, adjuvant, having a chemical or biochemical action, re-esterification process or any mixture with oils of other kinds are excluded from this category ${ }^{(11)}$. Extra-VOO are VOO with a free acidity, expressed as $g$ of oleic acid $/ 100 \mathrm{~g}$ of olive oil, less than $0.8 \mathrm{~g}$. VOO with an acidity greater than or equal to $3 \cdot 3$ (International Olive Oil Council Regulation/T.15/NC.n3.Rev2.Nov24, 2006) or greater than 2 in Europe (European Regulation No. 1513/0) are submitted to a refining process in which some components, mainly phenolic compounds, and to a lesser degree squalene, are lost ${ }^{(12)}$. By mixing virgin and refined olive oil, an ordinary olive oil (olive oil; EU regulation 2568/1991) is produced and marketed. After VOO production, the rest of the olive drupe and seed are submitted to a refining process, resulting in pomace olive oil, to which a certain quantity of VOO is added before marketing.

And, the key question is: What of the olive oils is the best when concerning nutritional purposes? With the data available at present, the response is extra-VOO (or extra-virgin olive oil) rich in phenolic compounds. In this review, we summarised the key work that has provided evidence of the benefits of VOO consumption over other types of edible oils, even olive oils. A literature review had been carried out in MEDLINE until August 2014. We searched for clinical studies assessing the effect of either acute (single dose) or sustained doses of VOO on the risk factors for CVD. Cohort studies that aimed to assess the relationship between olive oil consumption and end point for CVD were also included. Concerning the clinical trials, we refer to only randomised, controlled human studies, which are capable of providing the evidence of Level $\mathrm{I}^{(13)}$. According to Evidence-Based Medicine, the evidence of Level I is that required to perform nutritional recommendations at population level. Other types of studies including those performed in cellular or animal models were beyond the scope of the present review and thus were not included in the present review.

\section{Virgin olive oil, lipoproteins and lipoprotein oxidation}

The results of a meta-analysis of fourteen studies have shown that replacement of SFA by oils enriched in MUFA $v$. PUFA had similar effects on total-, LDL- and HDL-cholesterol. The PUFA-enriched oil had a slight TAG-lowering effect, and there was an increase in HDL-cholesterol after MUFA consumption in some studies ${ }^{(14)}$. However, despite the fact that no great differences in lipoprotein content exist between the consumption of MUFA and PUFA, there is an issue in which consumption of MUFA prevails over the consumption of PUFA: the lipoprotein oxidation. Oleate-rich LDL are less susceptible against oxidation than linoleate-rich particles ${ }^{(15)}$. This is due to the fact that PUFA are the key substrate for lipid peroxidation whose propagation chain is going on via the double bonds of the fatty $\operatorname{acid}^{(16)}$. From fourteen studies comparing the resistance of LDL to oxidation, only two studies have shown that MUFA-rich diets did not promote a higher resistance of LDL to oxidation than PUFA-rich $\operatorname{diets}^{(17)}$

Oxidation of the lipid part, or directly of the apoB, of the LDL leads to a change in the lipoprotein conformation by which the LDL is better able to enter into the monocyte/ macrophage system of the arterial wall and develop the atherosclerotic process ${ }^{(18,19)}$. Oxidised LDL has been shown to be independently associated with 10-year coronary artery disease events in general population, and improved the reclassification capacity of Framingham-derived coronary artery disease risk functions ${ }^{(20)}$. In addition, oxidation of HDL reduces the HDL functionality by impairing cholesterol efflux from macrophages ${ }^{(21)}$. Oleic acid consumption has been shown to reduce in vivo HDL oxidation in humans ${ }^{(22)}$. Phenolic compounds present in VOO have proven to be protective against LDL oxidation. On November 2011, the European Food Safety Authority released a claim concerning the benefits of daily ingestion of olive oil rich in phenolic compounds, such as VOO. The Panel considers that, in order to bear the claim, $5 \mathrm{mg}$ of hydroxytyrosol (OHTyr) and its derivatives (e.g. oleuropein complex and tyrosol (Tyr)) in olive oil should be consumed daily. These quantities, if provided by moderate amounts of olive oil, can be easily consumed in the context 
of a balanced diet ${ }^{(23)}$. Here, we revise the main studies that supported this European Food Safety Authority claim concerning the benefits of polyphenol-rich olive oils.

\section{Bioavailability of olive oil phenolic compounds in humans from real-life doses of natural olive oils}

Although non-absorbable phenolic compounds could show local antioxidant activities in the gastrointestinal $\operatorname{tract}^{(24)}$. One of the prerequisites for assessing the physiological significance of olive oil phenolic compounds is the ability to determine their bioavailability in human beings. Tyr and OHTyr, the main phenolic compounds in olive oil as free or conjugated forms ${ }^{(10,12)}$, are absorbed by humans in a dosedependent manner with the phenolic content of the olive oil administered $^{(25)}$. Despite a short half-life in the plasma (around $2.5 \mathrm{~h})^{(26)}$, both Tyr and OHTyr increase in plasma and urine in a dose-dependent manner after sustained olive oil consumption ${ }^{(27,28)}$. This implies an accumulation in the body even from moderate doses of olive oil $(25 \mathrm{ml} / \mathrm{d})$, which are lower than the traditional daily dietary intake in Mediterranean countries ${ }^{(29)}$. The bioavailability of OHTyr, however, has been shown to change largely depending on the matrix in which the phenolic compounds are administered, the most effective matrix being the olive oil ${ }^{(30)}$. Around $98 \%$ of Tyr and OHTyr are present in the plasma and urine in conjugated forms, glucuronoconjugates or sulphates. This fact indicates the existence of an extensive first-pass intestinal/hepatic metabolism of the ingested primary forms ${ }^{(26,31)}$. Data from experimental models also point out to a dose-dependent metabolic disposition of OHTyr, the main metabolites being the glucuronates or sulphates at low and high doses of OHTyr, respectively ${ }^{(32)}$.

\section{Human studies on the postprandial effect of olive oil on oxidative stress and oxidative damage}

After meals, particularly rich in fats, a postprandial hyperlipaemia and hyperglycaemia occurs, which is linked to oxidative stress. Although fasting hyperlipidaemia is considered an important risk for CVD, postprandial serum lipid levels have been found to correlate more closely to CVD than fasting lipids ${ }^{(33)}$. Activation of PPAR $\alpha$ suppresses postprandial lipidaemia through fatty acid oxidation in enterocytes $^{(34)}$. A functional olive oil enriched with its own phenolic compounds has shown to enhance the gene expression of PPAR $\alpha$ in mononuclear cells of pre-hypertensive and stage I hypertensive patients ${ }^{(35)}$

Several data on the effect of olive oil rich in phenolic compounds, such as VOO, on the postprandial oxidative stress have been reported. They are, however, difficult to compare because some studies do not mention whether or not postprandial lipaemia and/or hyperglycaemia occurs, which could lead to oxidative stress, after olive oil ingestion, while in other studies neither hyperlipaemia nor hyperglycaemia occurs at postprandial state after olive oil ingestion ${ }^{(9)}$. Ingestion of a $25 \mathrm{ml}$ olive oil dose did not promote postprandial oxidative stress independent of the phenolic content of the olive oil ${ }^{(36)}$, whereas single doses of $40 \mathrm{ml}^{(25)}$ and $50 \mathrm{ml}$ $\operatorname{did}^{(37)}$. With olive oil doses at which oxidative stress occurs, data from randomised, cross-over, controlled human studies showed (1) an increase in the serum antioxidant capacity after VOO ingestion, but not after ordinary olive oil, in comparison with maize oil, suggesting a role for the phenolic compounds of the $\mathrm{VOO}^{(38)}$; and (2) the phenolic content of an olive oil modulates the degree of lipid and LDL oxidation, the lipid oxidative damage being lower after high- than after low-phenolic content olive oil ${ }^{(25,39)}$. In comparison with sunflower oil, meals, submitted to a deep frying, with olive oils rich in phenolic compounds, both natural and added, have shown to reduce the postprandial oxidative stress in obese people ${ }^{(40)}$. Recently, it has been described that food fried in extra-VOO improves postprandial insulin response, an oxidative stress-associated phenomenae, in obese, insulin-resistant women ${ }^{(41)}$.

\section{Human studies of the sustained effect of olive oil on oxidative stress and oxidative damage}

Controversial results have been obtained in short sample size $(n<30)$, randomised, controlled human studies performed up to now on the effect of sustained doses of olive oil phenolic compounds on oxidative stress ${ }^{(42)}$. It must be pointed out that extensive differences existed among the studies in the experimental design, control of diet, sample population, age of participants, measurement or not of markers of the compliance of the intervention, as well as in the sensitivity and specificity of the oxidative stress biomarkers evaluated.

The results of the EUROLIVE (The effect of olive oil consumption on oxidative damage in European populations) study, however, have provided final evidence of the in vivo protective role of phenolic compounds from olive oil on lipid oxidative damage in humans, at real-life olive oil doses $^{(43)}$. The EUROLIVE study was a large, cross-over, multi-centre, clinical trial performed in 200 individuals from five European countries. Participants were randomly assigned to receive $25 \mathrm{ml} / \mathrm{d}$ of three similar olive oils, but with differences in their phenolic content (from 2.7 to $366 \mathrm{mg} / \mathrm{kg}$ of olive oil), in intervention periods of 3 weeks preceded by 2-week washout periods. All olive oils increased the HDLcholesterol and the ratio between the reduced and oxidised forms of glutathione. In the EUROLIVE study, consumption of medium- and high-phenolic content olive oil decreased lipid oxidative damage biomarkers such as plasma oxidised LDL, un-induced conjugated dienes and hydroxy fatty acids, without changes in $\mathrm{F}_{2}$-isoprostanes. However, the most important results of the EUROLIVE study were that an increase in HDL-cholesterol and a decrease in the lipid oxidative damage were linear with the phenolic content of the olive oil consumed. The results of the EUROLIVE study have provided the first level evidence that olive oil is more than a MUFA fat. Recent data from a subsample ( $n$ 990) of the PREDIMED study have shown that a MedDiet, only when enriched in VOO with high phenolic content $(316 \mathrm{mg} / \mathrm{kg})$, decreases the LDL oxidation in a significant manner compared with control group (low-fat diet) ${ }^{(44)}$, confirming previous data obtained ${ }^{(45)}$. 
HDL lipoprotein protects LDL from oxidation(46). Also, oxidation of HDL impairs HDL functionality rendering the lipoprotein less useful for the cholesterol efflux from macrophages ${ }^{(21,46)}$. From the results of the EUROLIVE study, a key question stems: Could phenolic compounds in VOO, besides to increase HDL quantity, also increase HDL functionality? Few data are available at present for answering this question. In a linear (non-randomised, not control group) study, extra-VOO consumption improves the capacity of HDL to mediate cholesterol efflux and increases ATP-binding membrane cassette system (ATP binding cassette transporter-A1 (ABCA1) and ATP binding cassette transporter-G1 (ABCG1)) expression, one of the main mechanisms for HDL-mediated cholesterol efflux from macrophages ${ }^{(47)}$. We recently performed a randomised, controlled clinical trial in which pre/ hypertensive patients were assigned $30 \mathrm{ml}$ of two similar olive oils with high $(961 \mathrm{mg} / \mathrm{kg}$, a functional VOO enriched with its phenolic compounds) and standard $(289 \mathrm{mg} / \mathrm{kg})$ phenolic content. The results indicate a significant role of olive oil polyphenols in the up-regulation of genes involved in the cholesterol efflux from cells to HDL in vivo in humans ${ }^{(35)}$. The fact that olive oil phenolic compounds increase the functionality of human HDL has been recently provided from a subsample of the EUROLIVE study. Highphenolic content olive oil increased the HDL-mediated cholesterol efflux from macrophages compared with lowphenolic content olive oil ${ }^{(48)}$. Thus, data are promising, and further randomised, controlled studies are required to establish the role of VOO and its phenolic compounds on HDL functionality.

Concerning DNA oxidative damage, the urinary excretion of 8-oxo-deoxyguanosine is advocated as a biomarker of the whole-body DNA oxidation ${ }^{(49)}$. Protective effects of olive oil phenolic compounds on in vivo DNA oxidation, measured as 8-oxo-deoxyguanosine in mononuclear cells and in urine, were found in healthy male subjects in a short-term study in which participants were submitted to a very low antioxidant diet $^{(28)}$. A protective effect on DNA oxidation, measured by the comet assay in peripheral blood lymphocytes, was observed in postmenopausal women ${ }^{(50)}$. Results of the EUROLIVE study, however, have shown that consumption of $25 \mathrm{ml}$ of olive oil per day during 3 weeks reduced DNA oxidation in 182 healthy males, as measured by the $24 \mathrm{~h}$ urinary excretion of 8-oxo-deoxyguanosine, irrespective of the phenolic content in olive oil ${ }^{(51)}$. Differences in the type of population involved (with or without oxidative stress) could explain the differences among the results. In this sense, one conclusion of the Consensus Report made by the Expert Panel in the International Conference of Olive Oil and Health held in Jaen, Spain, October $2004^{(8,52)}$, was that the protective effects on oxidation markers in human trials were better displayed in oxidative stress conditions.

Oxidative stress is linked to other pathological conditions present in chronic degenerative diseases such as inflammation, endothelial dysfunction, hypertension, etc. Here, we revise the available information related to concerning the role of VOO on these issues.

\section{Inflammation}

Oxidative stress is linked to other pathological conditions present in chronic degenerative diseases such as inflammation, endothelial dysfunction, hypertension, etc. Here, we revise the available information related to concerning the role of VOO on these issues.

Although the protective mechanism of oleic acid-rich diets on inflammation has been attributed to a decrease in the LDL linoleic acid content, oleic acid is not the single responsible factor for the anti-inflammatory properties of olive oil. The minor components of olive oil have been shown to have anti-inflammatory, antihypertensive and anti-endothelial activation properties in experimental studies ${ }^{(53)}$. Several studies have examined the anti-inflammatory and vasculoprotective effect of olive oil phenolic compounds in humans (Table 1). In these studies, VOO with high phenolic content has been shown to be effective in reducing the eicosanoid inflammatory mediators derived from arachidonic acid, such as thromboxane $\mathrm{B}_{2}$ and 6 -keto-PG $\mathrm{F}_{1} \alpha^{(38,54,55)}$, as well as other inflammatory markers, such as high-sensitivity C-reactive protein or IL- $6^{(56,57)}$. Concerning the effect on cell adhesion molecules, a decrease in serum intercellular adhesion molecule-1 (ICAM-1) and vascular cell adhesion molecule-1 levels at postprandial state after VOO ingestion when compared with refined olive oil ingestion has been reported ${ }^{(58)}$. Also, the postprandial inflammatory response after ingestion of heated oils in obese persons was reduced by the presence of oils with phenolic compounds or non-natural antioxidants $^{(59)}$. In this study ${ }^{(59)}$, although it is not possible to differentiate the effect of MUFA to that of olive oil phenolics, VOO or a mix of sunflower and rapeseed oil artificially enriched with olive oil phenolic compounds and other antioxidants, mitigated postprandial inflammation (reduced $\mathrm{NF}-\kappa \mathrm{B}$ activation, increased I $\mathrm{B}-\alpha$ and decreased lipopolysaccharide plasma concentration), compared with sunflower oil. In sustained consumption studies, no differences in ICAM-1 or vascular cell adhesion molecule-1 levels were reported after sustained virgin or refined olive oil consumption in CHD patients ${ }^{(56)}$. However, a decrease in ICAM-1 level after VOO ingestion, but not after VOO plus epigallocatechin3-galate ingestion, in early atherosclerosis patients has been reported ${ }^{(60)}$. The effect of olive oil polyphenols modulating, towards a protective mode, the expression of proinflammatory genes is described in the Nutrigenomic Section.

\section{Haemostasis, endothelial function and blood pressure}

The assessment of different aspects of endothelial dysfunction in cardiovascular medicine has been the focus of intense research and includes vasomotor, haemostatic, antioxidant and inflammatory activities ${ }^{(61)}$. The effect of VOO reducing oxidative stress and oxidative damage, as well as the inflammatory markers, has been described above. With respect to haemostatic factors, a huge body of work exists concerning the benefits of olive oil consumption reducing thrombogenesis through a decrease of coagulation factors and platelet aggregation $^{(62)}$. The role of specific olive oil components on these 
Table 1. Randomised, controlled studies on the effect of virgin olive oil (VOO) on inflammatory markers

\begin{tabular}{|c|c|c|c|c|c|}
\hline Subjects & Type of study & Intervention & Biomarkers & Effects & Authors \\
\hline Twelve postmenopausal women & $\begin{array}{l}\text { Two consecutive periods, no } \\
\text { washout diets ad libitum }\end{array}$ & VOO v. oleic acid-rich SFO & $\begin{array}{l}\mathrm{TXB}_{2} \text { in } \mathrm{PRP} \\
\mathrm{TXB}_{2} \text { in urine } \\
\text { 6-keto-PGF } \\
\mathrm{PG}_{1 \alpha}\end{array}$ & $\begin{array}{l}\text { Lower in VOO } \\
\text { Similar } \\
\text { Similar }\end{array}$ & Oubiña et al. ${ }^{(55)}$ \\
\hline $\begin{array}{l}\text { Hyperlipidaemic patients (twelve } \\
\text { men and ten women) }\end{array}$ & Randomised, cross-over & $\begin{array}{l}\text { VOO } v \text {. refined olive oil (inter- } \\
\text { vention, } 40 \mathrm{ml} / \mathrm{d}, 7 \text { weeks; } \\
\text { washout period, } 4 \text { weeks } \\
\text { with usual diet) }\end{array}$ & Serum $\mathrm{TXB}_{2}$ & $\begin{array}{l}\text { Decrease with the phenolic } \\
\text { content of olive oil }\end{array}$ & Visioli et al. ${ }^{(54)}$ \\
\hline Twelve healthy men & $\begin{array}{l}\text { Randomised, cross-over, } \\
\text { postprandial }\end{array}$ & $\begin{array}{l}\text { VOO } \mathrm{v} \text {. refined olive oil } \\
\text { (50 ml with potatoes) }\end{array}$ & $\begin{array}{l}\text { Plasma } \mathrm{LTB}_{4} \\
\text { Plasma } \mathrm{TXB}_{2}\end{array}$ & $\begin{array}{l}\text { Decrease with the phenolic } \\
\text { content of olive oil }\end{array}$ & Bogani et al. ${ }^{(38)}$ \\
\hline $\begin{array}{l}\text { Healthy (fourteen) and } \\
\text { hypertriglyceridaemic } \\
\text { (fourteen) men }\end{array}$ & $\begin{array}{l}\text { Randomised, cross-over, } \\
\text { postprandial }\end{array}$ & $\begin{array}{l}\text { Fat meal with VOO } v \text {. refined } \\
\text { olive oil, after } 1 \text { week of each } \\
\left(50 \mathrm{mg} / \mathrm{m}^{2} \text { body surface }\right)\end{array}$ & $\begin{array}{l}\text { Serum ICAM-1 and VCAM-1 } \\
\text { AUC }\end{array}$ & $\begin{array}{l}\text { Decrease with the phenolic } \\
\text { content of olive oil }\end{array}$ & Pacheco et al. \\
\hline Twenty-eight men with $\mathrm{CHD}$ & Randomised, cross-over & $\begin{array}{l}\text { VOO } v \text {. refined olive oil (inter- } \\
\text { vention period, } 50 \mathrm{ml} / \mathrm{d} \text {, } \\
3 \text { weeks; washout period, } \\
2 \text { weeks with refined olive oil } \\
\text { ad libitum) }\end{array}$ & $\begin{array}{l}\text { hs-CRP, IL-6 } \\
\text { Serum ICAM-1 and VCAM-1 }\end{array}$ & $\begin{array}{l}\text { Decrease with the phenolic } \\
\text { content of olive oil } \\
\text { No changes }\end{array}$ & Fitó et al. ${ }^{(57)}$ \\
\hline $\begin{array}{l}\text { Twenty-four women with } \\
\text { high-normal BP or stage } 1 \\
\text { essential hypertension }\end{array}$ & Randomised, cross-over & $\begin{array}{l}\text { Polyphenol-rich VOO }(30 \mathrm{mg} / \mathrm{d}) \\
\text { v. free polyphenol olive oil } \\
\text { (2-month; 4-week washout } \\
\text { period) }\end{array}$ & $\begin{array}{l}\text { ADMA } \\
\text { hs-CRP }\end{array}$ & $\begin{array}{l}\text { Decrease with the phenolic } \\
\text { content of olive oil }\end{array}$ & $\begin{array}{l}\text { Moreno-Luna } \\
\quad \text { et al. }{ }^{(58)}\end{array}$ \\
\hline Twenty obese participants & $\begin{array}{l}\text { Randomised, cross-over, } \\
\text { postprandial }\end{array}$ & $\begin{array}{l}\text { Breakfast with VOO, SFO and } \\
\text { SFO + canola oil (heated) } \\
\text { with added polyphenols or } \\
\text { artificial antioxidants }\end{array}$ & $\begin{array}{l}\text { TNF- } \alpha, \text { IL- } 1 \beta, \text { IL- } 6 \text {, } \\
\text { MIF, JNK and LPS } \\
\text { NF- } \mathrm{B} \text { and subunit activators }\end{array}$ & $\begin{array}{l}\text { Decrease with oils containing } \\
\text { polyphenols and antioxidants }\end{array}$ & $\begin{array}{l}\text { Pérez-Herrera } \\
\quad \text { et al. }{ }^{(60)}\end{array}$ \\
\hline $\begin{array}{l}\text { Eighty-two patients with early } \\
\text { atherosclerosis }\end{array}$ & Randomised, parallel & $\begin{array}{l}\text { VOO and VOO + EGCG } \\
(30 \mathrm{ml} / \mathrm{d}, 4 \text { months })\end{array}$ & $\begin{array}{l}\text { ICAM-1 } \\
\text { Leucocytes }\end{array}$ & Decrease with VOO & Widmer et al. ${ }^{(61)}$ \\
\hline
\end{tabular}

$\mathrm{BP}$, blood pressure; ADMA, asymmetric dimethylarginine; MIF, macrophage migration inhibitory factor; JNK, c-Jun N-terminal kinase; LPS, lipopolysaccharide. 
effects is, however, still controversial ${ }^{(62)}$. In randomised, controlled human studies, the intake of phenol-rich VOO, compared with a low-phenol one, improved the postprandial prothrombotic profile in healthy subjects ${ }^{(63)}$ and hypercholesterolaemic patients ${ }^{(64)}$. The role of phenolic compound-rich oils compared with a low-phenolic content oils on thromboxane $\mathrm{B}_{2}$, an inflammatory mediator and potent platelet aggregation inductor, has been discussed above (Table 1). Several studies have reported the beneficial effects of VOO on the endothelial function. An improved post-ischaemic hyperaemia via reduced oxidative stress and increased NO metabolites was reported after the intake of phenol-rich VOO in comparison with a low-phenol olive oil in hypercholesterolaemic patients ${ }^{(39)}$. The effect of VOO phenols on the postprandial endothelial function seems to be mediated by the NOS3 Glu298Asp polymorphism in patients with the metabolic syndrome ${ }^{(65)}$. Beneficial effects improving the endothelial function have been observed after a 4-month diet with polyphenol-rich olive oil in patients with early atherosclerosis ${ }^{(60)}$.

Consumption of olive oil is known to reduce blood pressure $^{(7)}$. However, phenolic compounds in VOO also play a beneficial role. A 2-month diet with olive oil rich in polyphenols decreased systolic (SBP) and diastolic blood pressure and improved endothelial function in young women with mild hypertension compared with the same diet with low-polyphenol content olive oil ${ }^{(57)}$. In this study ${ }^{(57)}$, changes in blood pressure and endothelial function were concomitant with markers related with vasodilatation, such as an increase in NO and a decrease in serum asymmetric dimethylarginine (ADMA), as well as a reduction in oxidised LDL and high-sensitivity C-reactive protein. VOO, but not high-oleic sunflower oil, reduced SBP in hypertensive women, indicating a role for the minor olive oil components on blood pressure levels ${ }^{(66)}$. A decrease in SBP after VOO consumption, in comparison with refined olive oil, in hypertensive stable patients with CHD has been reported ${ }^{(67)}$, together with a decrease in lipid oxidation. In a parallel study comparing the effect of VOO on blood pressure in diabetic patients and healthy individuals, a reduction in SBP was observed in both conditions ${ }^{(68)}$.

\section{Mechanisms by which virgin olive oil and its phenolic compounds can exert their benefits in vivo in humans}

There is a huge body of experimental studies concerning the mechanisms by which VOO and its phenolic compounds could exert their beneficial effects. From these, only two have been reported to occur in vivo in humans: (1) the increase in the antioxidant content of the LDL; (2) a nutrigenomic effect.

\section{Increase in the antioxidant content of the $L D L$}

Among the conclusions of the Consensus Report made by the Expert Panel in the International Conference of Olive Oil and Health held in Jaen, Spain, October $2004^{(9,52)}$, one of them was that, as a general rule, the best results obtained on lipid oxidation, after VOO consumption, were displayed in those markers directly associated with LDL oxidation. This could be explained on one hand by the fact that ingestion of any type of olive oil increases the plasma oleic acid content of the LDL lipoprotein. As has been referred to before, oleate-rich LDL are less susceptible against oxidation than linoleate-rich particles $^{(15)}$. Further results of the EUROLIVE study ${ }^{(69)}$ have shown that, after olive oil ingestion, oleic acid concentration in LDL increased and those of linoleic and arachidonic acid decreased. An inverse relationship between the oleic:linoleic acid ratio and biomarkers of oxidative stress was observed ${ }^{(69)}$. On the other hand, the total polyphenol content bound to human LDL increases in a dose-dependent manner with the phenolic content of the olive oil administered ${ }^{(25)}$. OHTyr and Tyr metabolites, glucuronides and sulphates have been reported to bind human LDL after VOO ingestion, but were not detected after refined olive oil ingestion ${ }^{(70)}$. Experimental data have shown that the susceptibility of LDL to oxidation depends not only on its fatty content but also on the LDL antioxidant content bound to the $\mathrm{LDL}^{(71)}$. In our previous work $^{(70)}$, we confirmed that this occurs in vivo in humans after VOO ingestion, given that an inverse relationship was obtained between plasma levels of oxidised LDL and the content of phenols bound to LDL. Phenolic compounds that can bind LDL are likely to perform their peroxyl scavenging activity in the arterial intima, where full LDL oxidation occurs $^{(18)}$.

\section{Nutrigenomic effect of virgin olive oil and its phenolic compounds}

Nutrigenomics embrace all 'omics' fields, such as genomics, transcriptomics, proteomics and metabonomics with the aim of understanding and characterising how nutrients and/or food act at molecular level. We here focus on the transcriptomic data available from randomised, controlled human studies, given that, at present, they are the only 'omic' data available. Particularly, we refer to studies in which different types of olive oils, but with differences in their phenolic content, have been tested with the same dietary pattern as background. Several studies have examined the transcriptomic profile of VOO in comparison with low-phenolic content olive oil at postprandial state. Using microarray techniques, it has been reported that a breakfast based on VOO, high in polyphenols (398 parts per million (ppm)), was able to postprandially repress the expression of proinflammatory genes when compared with a common olive oil-based breakfast (low in polyphenols, $70 \mathrm{ppm}$ ) in the metabolic syndrome individuals $^{(72)}$. Microarray results showed nineteen up-regulated and seventy-nine down-regulated genes, linked to obesity, dyslipaemia and type 2 diabetes mellitus, after the intake of $\mathrm{VOO}^{(72)}$. Also and as it has been referred before ${ }^{(35)}$, a VOO enriched with its own phenolic compounds enhanced the postprandial expression of cholesterol efflux-related genes in vivo in humans compared with a standard VOO. In our pre-hypertensive and stage I hypertensive patients, we observed an increase in $A B C A 1$, scavenger receptor class $\mathrm{B}$ type 1 (SR-B1), PPAR and binding protein (PPARBP, PPAR $\alpha$, $P P A R y$ and PPARS) and cluster of differentiation 36 (CD36) gene expression in leucocytes at postprandial state after 
high polyphenol VOO ingestion when compared with standard VOO ingestion ${ }^{(35)}$.

We also have data concerning the transcriptomic effect of VOO in sustained consumption studies. In the frame of the PREDIMED study, two studies have reported the differences when an enrichment of the MedDiet with VOO occurs. In the first study ${ }^{(73)}$, a 3-month intervention with VOO-enriched MedDiet prevented the increase in cyclooxigenase-2 (COX2) and LDL receptor-related protein (LRP1) genes, as well as reduced the expression of monocyte chemoattractant protein 1 (MCP1) gene, compared with a MedDiet enriched with nuts or with a low-fat diet. In the second, study ${ }^{(74)}$, we compared 3-month changes in the whole genome of peripheral blood mononuclear cells by means of whole transcriptome microarray analyses. Results of functional annotation analyses showed that from eighteen cardiovascular canonical pathways, nine were modulated by a MedDiet enriched with VOO and four when the MedDiet was enriched with nuts ${ }^{(74)}$. Also within the frame of a MedDiet, we have reported an in vivo nutrigenomic effect of VOO polyphenols in humans ${ }^{(75)}$. In this parallel, controlled, 3-month intervention trial, ninety healthy volunteers were randomised to three intervention dietary patterns: (1) MedDiet supplemented with polyphenol-rich VOO $(328 \mathrm{mg} / \mathrm{kg})$; (2) MedDiet supplemented with washed VOO (low in polyphenols: $55 \mathrm{mg}$ / $\mathrm{kg}$ ); (3) control group with their habitual diet. Only after the supplementation of MedDiet with polyphenol-rich VOO, there was a significant decrease, $v$. the control group, in the expression of genes related with inflammation: interferon $\gamma$ $(I F N \gamma)$, Rho GTPase activating protein 15 (ARHGAP15) and IL-7 receptor $(I L 7 R)$; and oxidative stress: adrenergic $\beta-2$ receptor (ADRB2). Changes in gene expression after the MedDiet supplemented with VOO were concomitant with decreases in lipid oxidative damage and systemic inflammation markers ${ }^{(75)}$. In a substudy of the EUROLIVE study, we proposed for the first time an integrated scheme for the in vivo down-regulation of the CD40/CD40L system and its downstream products promoted by the consumption of $\mathrm{VOO}^{(76)}$. Our results showed a decrease in the expression of pro-atherogenic genes: CD40 antigen ligand (CD4OL), IL-23A (IL23A), ADRB2, oxidised LDL (lectin-like) receptor 1 (OLR1), IL-8 receptor-a (IL8RA) and $I L 7 R$ ) after consumption of VOO high in polyphenols when compared with the refined olive oil, low in polyphenols. The decrease in these genes was concomitant with the decreasing trend of the interlinked genes such as vascular endothelial growth factor (VEGF), ICAM1 and $M C P 1$. In this study ${ }^{(76)}$, the reduction in LDL oxidation and the increase in antioxidant polyphenols in LDL promoted by the regular dietary intake of polyphenolrich VOO were associated with a down-regulation in the expression of genes related with the CD40/CD40L pathway. Fried sunflower oil, incorporated into muffins, but not VOO or oil to which natural antioxidants of the olives have been added, induced the postprandial increase in the mRNA levels of the endothelial reticulum stress-sensor serum X-box binding protein 1 (SXBP1), and the endothelial reticulum stress-related chaperones sbinding immunoglobulin protein (BiP) and calreticulin $(\mathrm{CRT})^{(77)}$. Due to all referred above,
VOO and its phenolic compounds can modulate the expression of atherosclerosis-related genes towards a protective mode in vivo in humans.

\section{Strengths and limitations}

The design of clinical trials referred to in this review has several strengths. As has been referred to previously, all the included trials were of a randomised, controlled design. A large part of them were cross-over, thus permitted the same participants to be included in the different olive oil interventions, thus, minimising the interferences with other possible confounder variables. However, these studies also have limitations. One of them is the inability to determine whether the changes in cardiovascular risk factors could be attributed to a specific VOO component (e.g. phenolic compounds), an interaction among olive oil components (e.g. phenolic content plus MUFA), or among olive oil components and others from diet. It is difficult to separate the biological actions of nutrients from the global dietary pattern. In addition, the measurements of dietary intake relied on self-reporting and were, therefore, subjective. Also, the determination of the phenolic content of an olive oil has methodological difficulties, and a large variability exists between procedures. Another limitation is the short duration of the intervention periods, in the cross-over studies. It is unknown whether additional or different effects would have been observed over longer periods. A longer duration of the studies, however, could have impaired the compliance of the participants.

\section{Conclusions}

From all the data referred to in this review, the question: Why to choose VOO? can be answered. VOO has shown to promote additional benefits to those provided by other vegetable oils on the following: (1) increasing HDL-cholesterol; (2) reducing the oxidative damage to lipids; (3) decreasing inflammation; (4) improving endothelial function; (5) decreasing SBP. Mechanisms by which VOO can exert its beneficial effects are the increase in the antioxidant content of LDL and a nutrigenomic effect, modulating the expression of atherosclerosis-related genes towards a protective mode.

\section{Acknowledgements}

CIBEROBN is an initiative of the Instituto de Salud Carlos III, Madrid, Spain.

The authors' contributions are as follows: M.-I. C. prepared the first draft and the final version of the manuscript; M. F. and R. d. 1. T. revised the first draft and made useful remarks, and revised the final version of the manuscript.

None of the authors has any conflict of interest to declare.

\section{References}

1. Estruch R, Ros E, Salas-Salvadó J, et al. (2013) Primary prevention of cardiovascular disease with a Mediterranean diet. $N$ Engl J Med 368, 1279-1290. 
2. Buckland G, Mayén AL, Agudo A, et al. (2012) Olive oil intake and mortality within the Spanish population (EPIC-Spain). Am J Clin Nutr 96, 142-149.

3. Buckland G, Travier N, Barricarte A, et al. (2012) Olive oil intake and CHD in the European Prospective Investigation into Cancer and Nutrition Spanish cohort. Br J Nutr 108, 2075-2082

4. Bendinelli B, Masala G, Saieva C, et al. (2011) Fruit, vegetables, and olive oil and risk of coronary heart disease in Italian women: the EPICOR Study. Am J Clin Nutr 93, $275-283$

5. Samieri C, Féart C, Proust-Lima C, et al. (2011) Olive oil consumption, plasma oleic acid, and stroke incidence: the Three-City Study. Neurology 77, 418-425.

6. Martínez-Gonzalez MA, Toledo E, Arós F, et al. (2014) Extra-virgin olive oil consumption reduces the risk of atrial fibrillation. The PREDIMED (prevención con Diet Mediterránea) Trial. Circulation 130, 18-26.

7. López-Miranda J, Pérez-Jiménez F, Ros E, et al. (2010) Olive oil and health: summary of the II international conference on olive oil and health consensus report, Jaen and Córdoba (Spain) 2008. Nutr Metab Cardiovasc Dis 20, 284-294.

8. US Food and Drug Administration (2004) Press Release P04100, 1 November. http://www.fda.gov/bbs/topics/news/ 2004/NEW01129.htlm (accessed 28 March 2014).

9. Covas MI, Ruiz-Gutiérrez V, de la Torre R, et al. (2006) Minor components of olive oil: evidence to date of health benefits in humans. Nutr Rev 64, Suppl. 1, 20-30.

10. Gimeno E, Castellote AI, Lamuela-Raventós RM, et al. (2002) The effect of harvest and extraction methods on the antioxidant content (phenolics, $\alpha$-tocopherol, and $\beta$-carotene) in virgin olive oil. Food Chem 78, 207-211.

11. European Union Commission (2001) Council Regulation (EC) 1513/2001 of 23 July 2001 amending regulation (EC) $136 / 66 /$ EEC and 1638/98 as regards the extension of the period of validity of the aid scheme and the quality strategy for olive oil. Off J Eur Comm L201, 4-7.

12. Owen RW, Mier W, Giacosa A, et al. (2000) Phenolic compounds and squalene in olive oils: the concentration and antioxidant potential of total phenols, simple phenols, secoiridoids, lignans and squalene. Food Chem Toxicol 38 , 647-659

13. Woolf SH, Battista RN, Anderson GM, et al. (1990) Assessing the clinical effectiveness of preventive maneuvers: analytic principles and systematic methods in reviewing evidence and developing clinical practice recommendations. A report by the Canadian Task Force on the Periodic Health Examination. J Clin Epidemiol 43, 891-905.

14. Gardner CD \& Kraemer HC (1995) Monounsaturated versus polyunsaturated dietary fat and serum lipids. A meta-analysis. Arterioscler Thromb Vasc Biol 15, 1917-1927.

15. Reaven P, Parthasarathy S, Grasse BJ, et al. (1993) Effects of oleate-rich and linoleate-rich diets on the susceptibility of low density lipoprotein to oxidative modification in mildly hypercholesterolemic subjects. Clin Invest 91, 668-676.

16. Gutteridge JMC (1995) Lipid peroxidation and antioxidants as biomarkers of tissue damage. Clin Chem 41, 1819-1828.

17. Lapointe A, Couillard C \& Lemieux S (2006) Effects of dietary factors on oxidation of low-density lipoprotein particles J Nutr Biochem 17, 645-658.

18. Witzum JL (1994) The oxidation hypothesis of atherosclerosis. Lancet 344, 793-795.

19. Steinberg D, Parthasarathy S, Carew TE, et al. (1989) Beyond cholesterol. Modifications of low density lipoprotein that increase its atherogenicity. $N$ Engl J Med 320, 915-924.
20. Gómez M, Vila J, Elosua R, et al. (2014) Relationship of lipid oxidation with subclinical atherosclerosis and 10-year coronary events in general population. Atherosclerosis 232, 134-140.

21. Girona J, LaVille AE, Solà R, et al. (2003) HDL derived from the different phases of conjugated diene formation reduces membrane fluidity and contributes to a decrease in free cholesterol efflux from human THP-1 macrophages. Biochim Biophys Acta 1633, 143-148.

22. Solà R, La Ville AE, Richard JL, et al. (1997) Oleic acid rich diet protects against the oxidative modification of high density lipoprotein. Free Radic Biol Med 22, 1037-1045.

23. EFSA Panel on Dietetic Products, Nutrition and allergies (NDA) (2011) Scientific opinion on the substantiation of health claims related to polyphenols in olive oil and protection of LDL particles from oxidative damage. EFSA J 9, 2033. http://www.efsa.europa.eu/en/efsajournal/pub/2033. htm (accessed on January 2014).

24. Ursini F, Zamburlini A, Cazzolato G, et al. (1998) Postprandial plasma lipid hydroperoxides: a possible link between diet and atherosclerosis. Free Radic Biol Med 25, 250-252.

25. Covas MI, de la Torre K, Farré-Albaladejo M, et al. (2006) Postprandial LDL phenolic content and LDL oxidation are modulated by olive oil phenolic compounds in humans. Free Radic Biol Med 40, 608-616.

26. Miró-Casas E, Covas MI, Farré M, et al. (2003) Hydroxytyrosol disposition in humans. Clin Chem 49, 945-952.

27. Marrugat J, Covas MI, Fitó M, et al. (2004) Effects of differing phenolic content in dietary olive oils on lipids and LDL oxidation. A randomized controlled trial. Eur J Nutr $\mathbf{4 3}$, 140-147.

28. Weinbrenner T, Fitó M, de la Torre R, et al. (2004) Olive oils high in phenolic compounds modulate oxidative/antioxidative status in men. $J$ Nutr 134, 2314-2321.

29. Helsing E (1995) Traditional diets and disease patterns of the Mediterranean, circa 1960. Am J Clin Nutr 61, 6 Suppl., 1329S-1337S

30. Visioli F, Galli C, Grande S, et al. (2003) Hydroxytyrosol excretion differs between rats and humans and depends on the vehicle of administration. J Nutr 133, 2612-2615.

31. Kotronoulas A, Pizarro N, Serra A, et al. (2013) Dose-dependent metabolic disposition of hydroxytyrosol and formation of mercapturates in rats. Pharmacol Res 77, 47-56.

32. Rubió L, Valls RM, Macià A, et al. (2012) Impact of olive oil phenolic concentration on human plasmatic phenolic metabolites. Food Chem 135, 2922-2929.

33. Roche HM \& Gibney MJ (2000) The impact of postprandial lipemia in accelerating atherothrombosis. J Cardiovasc Risk 7, 317-324.

34. Kimura R, Takahashi N, Murota K, et al. (2011) Activation of peroxisome proliferator-activated receptor- $\alpha$ (PPAR $\alpha)$ suppresses postprandial lipidemia through fatty acid oxidation in enterocytes. Biochem Biophys Res Commun 410, 1-6.

35. Farràs M, Valls RM, Fernández-Castillejo S, et al. (2013) Olive oil polyphenols enhance the expression of cholesterol efflux related genes in vivo in humans. A randomized controlled trial. J Nutr Biochem 24, 1334-1339.

36. Weinbrenner T, Fitó M, Farré-Albaladejo M, et al. (2004) Bioavailability of olive oil phenolic compounds from olive oil and oxidative/antioxidative status at postprandial state in humans. Drugs Exp Clin Res 30, 207-212.

37. Fitó M, Gimeno E, Covas MI, et al. (2002) Postprandial and short-term effects of dietary virgin olive oil on oxidant/antioxidant status. Lipids 37, 245-251. 
38. Bogani P, Galli C, Villa M, et al. (2007) Postprandial antiinflammatory and antioxidant effects of extra virgin olive oil. Atherosclerosis 190, 181-186.

39. Ruano J, López-Miranda J, Fuentes F, et al. (2005) Phenolic content of virgin olive oil improves ischemic reactive hyperemia in hypercholesterolemic patients. J Am Coll Cardiol 46, $1864-1868$.

40. Pérez-Herrera A, Rangel-Zuñiga OA, Delgado-Lista J, et al. (2013) The antioxidants in oils heated at frying temperature, whether natural or added, could protect against postprandial oxidative stress in obese people. Food Chem 138, 2250-2259.

41. Farnetti S, Malandrino N, Luciani D, et al. (2011) Food fried in extra-virgin olive oil improves postprandial insulin response in obese, insulin-resistant women. J Med Food 14, 316-321.

42. Fitó M, de la Torre R \& Covas MI (2007) Olive oil and oxidative stress. Mol Nutr Food Res 51, 1215-1224.

43. Covas MI, Nyyssönen K, Poulsen HE, et al. (2006) The effect of polyphenols in olive oil on heart disease risk factors. Ann Intern Med 145, 333-341.

44. Fitó M, Estruch R, Salas-Salvadó J, et al. (2014) Effect of the Mediterranean diet on heart failure biomarkers: a randomized sample from the PREDIMED trial. Eur J Heart Fail 16, 543-550.

45. Fitó M, Guxens M, Corella D, et al. (2007) Effect of a traditional Mediterranean diet on lipoprotein oxidation: a randomized controlled trial. Arch Intern Med 167, $1195-1203$.

46. Fogelman AM (2004) When good cholesterol goes bad. Nat Med 10, 902-903.

47. Helal O, Berrougui H, Loued S, et al. (2013) Extra-virgin olive oil consumption improves the capacity of HDL to mediate cholesterol efflux and increases $A B C A 1$ and $A B C G 1$ expression in human macrophages. $B r J$ Nutr 109, 1844-1855.

48. Hernáez A, Fernández-Castillero S, Farràs M, et al. (2014) Olive oil polyphenols enhance high density lipoprotein function in humans. A randomized controlled trial. Arterioscler Thromb Vasc Biol 34, 2115-2119.

49. Poulsen HE (2005) Oxidative DNA modifications. Exp Toxicol Pathol 57, 161-169.

50. Salvini S, Sera F, Caruso D, et al. (2006) Daily consumption of a high-phenol extra-virgin olive oil reduces oxidative DNA damage in postmenopausal women. Br J Nutr 95 , 742-751.

51. Machowetz A, Poulsen HE, Gruendel S, et al. (2007) Effect of olive oils on biomarkers of oxidative DNA stress in North and South Europeans. FASEB J 21, 45-52.

52. Pérez-Jimenez F, Alvarez de Cienfuegos G, Badimon L, et al. (2004) International Conference on the healthy effect of virgin olive oil. Consensus Report, Jaen (Spain). Eur J Clin Invest 35, 421-424.

53. Perona JS, Cabello-Moruno R \& Ruiz-Gutierrez V (2006) The role of virgin olive oil components in the modulation of endothelial function. $J$ Nutr Biochem 17, 429-445.

54. Visioli F, Caruso D, Grande S, et al. (2005) Virgin olive oil study (VOLOS): vasoprotective potential of extra virgin olive oil in mildly dyslipidemic patients. Eur J Nutr $\mathbf{4 4}$, $121-127$.

55. Oubiña P, Sanchez-Muniz FJ, Rodenas S, et al. (2001) Eicosanoid production, thrombogenic ratio, and serum and LDL peroxides in normo- and hypercholesterolaemic postmenopausal women consuming two oleic acid-rich diets with different content of minor components. Br J Nutr $\mathbf{8 5}$, $41-47$.
56. Fitó M, Cladellas M, de la Torre R, et al. (2008) Antiinflammatory effect of virgin olive oil in stable coronary disease patients: a randomized, crossover, controlled trial. Eur J Clin Nutr 62, 570-574.

57. Moreno-Luna R, Muñoz-Hernandez R, Miranda ML, et al. (2012) Olive oil polyphenols decrease blood pressure and improve endothelial function in young women with mild hypertension. Am J Hypertens 25, 1299-1304.

58. Pacheco YM, Bermúdez B, Lopez S, et al. (2007) Minor compounds of olive oil have postprandial anti-inflammatory effects. Br J Nutr 98, 260-263.

59. Pérez-Herrera A, Delgado-Lista J, Torres-Sanchez LA, et al. (2012) The postprandial inflammatory response after ingestion of heated oils in obese persons is reduced by the presence of phenol compounds. Mol Nutr Food Res 56, $510-514$

60. Widmer RJ, Freund MA, Flammer AJ, et al. (2013) Beneficial effects of polyphenol-rich olive oil in patients with early atherosclerosis. Eur J Nutr 52, 1223-1231.

61. Shantsila E, Wrigley BJ, Blann AD, et al. (2012) A contemporary view on endothelial function in heart failure. Eur $J$ Heart Fail 14, 873-881.

62. Delgado-Lista J, García-Rios A, Pérez-Martínez P, et al. (2011) Olive oil and haemostasis: platelet function, thrombogenesis and fibrinolysis. Curr Pharm Design 17, 778-785.

63. Pacheco YM, Lopez S, Bermudez B, et al. (2006) Extravirgin vs. refined olive oil on postprandial hemostatic markers in healthy subjects. J Thromb Haemost 4, 1421-1422.

64. Ruano J, Lopez-Miranda J, de la Torre R, et al. (2007) Intake of phenol-rich virgin olive oil improves the postprandial prothrombotic profile in hypercholesterolemic patients. Am J Clin Nutr 86, 341-346.

65. Jiménez-Morales AI, Ruano J, Delgado-Lista J, et al. (2011) NOS3 Glu298Asp polymorphism interacts with virgin olive oil phenols to determine the postprandial endothelial function in patients with the metabolic syndrome. $J$ Clin Endocrinol Metab 96, E1694-E1702.

66. Ruiz-Gutierrez V, Muriana FJ, Guerrero A, et al. (1996) Plasma lipids, erythrocyte membrane lipids and blood pressure of hypertensive women after ingestion of dietary oleic acid from two different sources. J Hypertens 14, 1483-1490.

67. Fitó M, Cladellas M, de la Torre R, et al. (2005) Antioxidant effect of virgin olive oil in patients with stable coronary heart disease: a randomised, crossover, controlled, clinical trial. Atherosclerosis 181, 149-158.

68. Perona JS, Montero E, Sánchez-Domínguez JM, et al. (2009) Evaluation of the effect of dietary virgin olive oil on blood pressure and lipid composition of serum and low-density lipoprotein in elderly type 2 diabetic subjects. J Agric Food Chem 57, 11427-11433.

69. Cicero AFG, Nascetti S, López-Sabater MC, et al. (2008) Changes in LDL fatty acid composition as a response to olive oil treatment are inversely related to lipid oxidative damage: The EUROLIVE Study. J Am Coll Nutr 27, 314-320.

70. De la Torre-Carbot K, Chávez-Servín JL, Jaúregui $\mathrm{O}$, et al. (2010) Elevated circulating LDL phenol levels in men who consumed virgin rather than refined olive oil are associated with less oxidation of plasma LDL. J Nutr 140, 501-508.

71. Fuller CJ \& Jialal I (1994) Effects of antioxidants and fatty acids on low density lipoprotein oxidation. Am J Clin Nutr 60, 1010-1013.

72. Camargo A, Ruano J, Fernandez J M, et al. (2010) Gene expression changes in mononuclear cells in patients with metabolic syndrome after acute intake of phenol-rich virgin olive oil. BMC Genomics 11, 253. 
73. Llorente-Cortes V, Estruch R, Mena MP, et al. (2010) Effect of Mediterranean diet on the expression of proatherogenic genes in a population at high cardiovascular risk. Atherosclerosis 208, 442-450.

74. Castañer O, Corella D, Covas MI, et al. (2013) In vivo transcriptomic profile after a Mediterranean diet in high cardiovascular risk patients. A randomized controlled trial. Am J Clin Nutr 98, 845-853.

75. Konstantinidou V, Covas MI, Muñoz-Aguayo D, et al. (2010) In vivo nutrigenomic effects of virgin olive oil polyphenols within the frame of the Mediterranean diet: a randomized controlled trial. FASEB J 24, 2546-2557.

76. Castañer O, Covas MI, Khymenets O, et al. (2012) Protection of LDL from oxidation by olive oil polyphenols is associated with a downregulation of CD40-ligand expression and its downstream products in vivo in humans. Am J Clin Nutr 95, 1238-1244.

77. Rangel-Zúñiga OA, Haro C, Pérez-Martínez P, et al. (2014) Effect of frying oils on the postprandial endoplasmic reticulum stress in obese people. Mol Nutr Food Res 58, $2239-2242$ 